\title{
Frutificação, características físicas de frutos e produtividade em cultivares e seleções de pessegueiro em Vista Alegre do Alto-SP
}

\author{
Fruiting, physical fruit characteristics and productivity of peach tree \\ cultivars and selections in Vista Alegre do Alto, São Paulo State, Brazil
}

\author{
Fernando Mendes Pereira' ${ }^{I}$ Newton Alex Mayer ${ }^{I I}$
}

RESUMO

A microrregião de Jaboticabal, SP, considerada como marginal para o cultivo do pessegueiro, apresenta vantagens comparativas importantes em relação às principais regiões produtoras do Brasil, como o reduzido risco de geadas, a baixa umidade relativa do ar e o déficit hídrico entre abril e setembro, além da possibilidade de produção precoce (agosto a outubro), o que tem remunerado satisfatoriamente os produtores. Entretanto, os resultados de pesquisa são consistentes apenas para a cultivar "Aurora-1". Visando consolidar esta microrregião como um novo pólo produtor de pêssegos de alta qualidade, o presente trabalho foi realizado no município de Vista Alegre do Alto-SP e teve por objetivo estudar a frutificação, as características físicas de frutos e a produtividade das cultivares "Aurora-1" e "Régis" e das seleções "Jab 484" e "Jab 694". Com as avaliações realizadas no $2^{\circ}$ e no $3^{\circ}$ ano após o transplantio das mudas (safras de 2005 e 2006), foi possível concluir que: a) a frutificação das cultivares "Régis" e "Aurora-1" e das seleções "Jab 484" $e$ "Jab 694"é satisfatória em condições climáticas normais do município de Vista Alegre do Alto-SP; b) a cultivar "Régis" pode apresentar produção e produtividade equivalentes à "Aurora-1", podendo se tornar opção para produção ultraprecoce com frutos de dupla finalidade, ainda que sejam menores e mais leves em relação à "Aurora-1", "Jab 484" $e$ "Jab 694”; c) as seleções "Jab 484” e "Jab 694” apresentam potencial para o cultivo em Vista Alegre do Alto-SP, por apresentarem frutos com características de dupla finalidade (servem para consumo in natura e para processamento), por serem mais pesados que "Aurora-1", podendo atingir produção e produtividade equivalentes a esta cultivar.

Palavras-chave: frutas de caroço, Prunus spp., inverno ameno, baixa exigência de frio.

\section{ABSTRACT}

The Jaboticabal Micro-region, located in São Paulo State, Brazil, considered unsuitable for peach tree culture, presents important comparative advantages in relation to other traditional regions producing peach in Brazil, as the reduced frost incidence, low air relative humidity and hidric deficit between April and September, beyond precocious production possibility (August to October), which has remunerated satisfactorily the fruit growers. However, the research results are consistent only to 'Aurora-1' peach. Aiming to consolidate this Micro-region as a new peach production pole of high quality, the present research was conducted in Vista Alegre do Alto, São Paulo State, and had the objective to study the fruiting, physical fruit characteristics and productivity of 'Aurora-1' and 'Régis' cultivar, and 'Jab 484' and 'Jab 694' peach selections. With the evaluations carried through in $2^{\text {nd }}$ and $3^{\text {rd }}$ years after transplant (2005 and 2006 harvests), it was possible to conclude that: a) the fruiting of 'Régis' and 'Aurora-1' cultivars and 'Jab 484' and 'Jab 694' peach selections is satisfactory in normal climatic conditions in Vista Alegre do Alto, São Paulo State, Brazil; b) 'Régis' peach tree presents production and productivity equivalent to 'Aurora-1', becoming an option for ultraprecocious production of double purpose fruits, despite its fruits being smaller and lighter than 'Aurora1 ' peach, 'Jab 484' and 'Jab 694' peach selections; c) 'Jab 484' and 'Jab 694' peach selections present potential in Vista Alegre do Alto, São Paulo State, presenting fruits with double purpose characteristics, being heavier than 'Aurora-1' peach, being able to reach production and productivity equivalent to this cultivar.

Key words: stone fruits, Prunus spp., mild winter, low chill requirement

\section{INTRODUÇÃO}

No Brasil, a cultura do pessegueiro dispõe de inúmeras cultivares com diferentes exigências térmicas em número de horas de frio para superação da

\footnotetext{
IDepartamento de Produção Vegetal, Faculdade de Ciências Agrárias e Veterinárias (FCAV), Universidade Estadual Paulista (UNESP), Via de Acesso Prof. Paulo Donato Castellane s/n, 14884-900, Jaboticabal, SP, Brasil. E-mail: mayersul@yahoo.com.br IEmbrapa Clima Temperado, BR 392, Km 78, CP 403, 96001-970, Pelotas, RS, Brasil. E-mail: abr@cpact.embrapa.br. Autor para correspondência.
} 
endodormência, graças aos resultados obtidos com os programas de melhoramento genético existentes (BARBOSA et al., 1997; RASEIRA \& NAKASU, 1998). Além de os significativos avanços com o melhoramento genético, destaca-se também o desenvolvimento e o uso de tecnologias auxiliares, que viabilizam o cultivo do pessegueiro em regiões consideradas "marginais", tais como a irrigação, o adensamento de pomares, a aplicação da cianamida hidrogenada, a dupla poda anual (de renovação, em outubro-novembro, e outra de produção, de maio até final de julho) e a poda drástica bienal. Com a disponibilidade de cultivares menos exigentes em frio e com o uso de tecnologias auxiliares, a cultura do pessegueiro no Brasil tem se expandido para regiões não tradicionais e com baixas latitudes, como no norte do Estado de São Paulo, no Espírito Santo e até nos altiplanos de Goiás (OGATA, 1988; CATI, 1997; NIENOW, 1997; PEREIRA et al., 2002; BARBOSA et al., 2003; ESPÍRITO SANTO, 2007).

A microrregião de Jaboticabal, SP, pertencente a mesorregião de Ribeirão Preto, é composta por 17 municípios, segundo a classificação do IBGE. Essa microrregião caracteriza-se especialmente pela concentração de chuvas entre os meses de outubro e março e por uma estação seca com deficiência hídrica, entre abril e setembro (VOLPE, 2000a.; VOLPE, 2000b.). No município de Jaboticabal, o número de horas com temperaturas iguais ou abaixo de $7,0^{\circ} \mathrm{C}$ é de apenas 17,9 horas por ano e a ocorrência de temperaturas iguais ou inferiores a $13,0^{\circ} \mathrm{C}$, ao nível de $50 \%$ de probabilidade, é de 312 horas anuais (YAMANAKA, 1992). O inverno apresenta baixo risco de formação de geadas, sendo registrados apenas 24 dias com geadas entre 1971 e 2000 (VOLPE, 2000c.). Segundo a classificação de Köppen, o clima da microrregião é do tipo Cwa, ou seja, mesotérmico com verões quentes e chuvosos e inverno seco.

As condições climáticas existentes na microrregião de Jaboticabal e a lacuna existente no mercado para pêssegos precoces de alta qualidade foram os elementos que impulsionaram para a realização de um amplo projeto na Faculdade de Ciências Agrárias e Veterinárias (FCAV/UNESP, Campus de Jaboticabal) para viabilizar o cultivo comercial do pessegueiro. Após 20 anos de pesquisas, foram testadas 15 cultivares de pessegueiros e de nectarineiras e os resultados foram consistentes e viáveis comercialmente somente para a cultivar “Aurora-1” (PEREIRA et al., 2002). Visando consolidar a região como produtora de pêssegos de alta qualidade, observou-se a necessidade de se estudar outras cultivares e seleções adaptadas, buscando, especialmente, a ampliação do período de colheita com cultivares de dupla finalidade.
Em trabalho de melhoramento genético realizado em São Carlos, SP, foram selecionadas “Jab 484" e "Jab 694”, ambas originárias de seedlings da cultivar "Biuti” de polinização aberta, as quais apresentam características superiores ao seu progenitor. A “Jab 484” foi selecionada por apresentar coloração avermelhada da periderme, tornando o fruto competitivo no mercado in natura, embora os frutos sejam menores que "Biuti”, enquanto que "Jab 694", além de apresentar qualidades iguais à “Jab 484”, com exceção da coloração da película e ausência completa de auréola em torno do endocarpo, produz frutos iguais ou até maiores que "Biuti”. Ambas as seleções foram testadas na microrregião de Jaboticabal e consideradas promissoras (SALLES, 1997; SALLES, 2002). Entretanto, é necessária a obtenção de maiores informações sobre estas seleções, especialmente com relação à produção e produtividade em espaçamentos de plantio recomendados e com a tecnologia disponível para plantios comerciais na região (PEREIRA et al., 2002). Testes preliminares realizados na microrregião de Jaboticabal também indicaram potencial com a cultivar "Régis" (OJIMA et al., 1991), especialmente pela abundante produção de flores e pelo reduzido ciclo entre a florada e a colheita.

Visando consolidar a microrregião de Jaboticabal como um novo pólo produtor de pêssegos de alta qualidade, o presente trabalho tem por objetivo estudar a frutificação, as características físicas de frutos e a produtividade das cultivares "Aurora-1" e "Régis" e das seleções “Jab 484” e "Jab 694”, nas safras de 2005 e de 2006, no Município de Vista Alegre do AltoSP.

\section{MATERIAL E MÉTODOS}

Para a instalação do experimento, foram produzidas mudas de pessegueiro [Prunus persica (L.) Batsch] das cultivares “Aurora-1” (OJIMA et al., 1989) e "Régis” (OJIMA et al., 1991), além das seleções “Jab 484” e “Jab 694” (SALLES, 1997; SALLES, 2002), por meio de enxertia de borbulhia em escudo modificada (PEREIRA \& MAYER, 2005). As seleções “Jab 484” e “Jab 694” são oriundas de seedlings da cv. "Biuti” de polinização aberta, testadas na microrregião de Jaboticabal, SP, onde apresentaram potencial de cultivo e características superiores ao seu progenitor (SALLES, 1997; SALLES, 2002). O porta-enxerto utilizado foi a cultivar “Okinawa” [Prunus persica (L.) Batsch], propagada por germinação de sementes após estratificação em geladeira (PEREIRA \& MAYER, 2005). Durante toda a fase de viveiro, os porta-enxertos foram 
mantidos em sacos plásticos perfurados $(28 \times 18 \mathrm{~cm})$ contendo substrato comercial (Rendmax Citrus ${ }^{\circledR}$ ).

O experimento foi instalado na Fazenda Santa Alzira, localizada no Município de Vista Alegre do Alto, SP (2110’14” S, 48³7’45” W, 700m de altitude), pertencente à microrregião de Jaboticabal. O solo do local é classificado como Argissolo Vermelho-Amarelo eutrófico de textura arenosa média (OLIVEIRA et al., 1999). A correção da acidez do solo foi feita com calagem para elevar a saturação por bases a 70\% e manter o teor de Mg no mínimo em $9 \mathrm{mmol} \mathrm{dm}^{-3}$ (RAIJ et al., 1996). O corretivo foi aplicado em todo o terreno e incorporado mediante aração e gradagem. As covas foram preparadas ( $50 \times 50 \times 50 \mathrm{~cm})$, adotando-se o espaçamento de 6 x 4m. A adubação de instalação consistiu na aplicação dos seguintes produtos, por cova: $20 \mathrm{~kg}$ de esterco de bovinos curtido; 1 a 1,5kg de superfosfato simples e $60 \mathrm{~g}$ de $\mathrm{K}_{2} \mathrm{O}$ (PEREIRA et al., 2002). Transcorridos 30 dias da aplicação dos fertilizantes, as mudas foram transplantadas (agosto de 2003), mantendo-se o torrão intacto. Em seguida, as hastes principais foram podadas a $50 \mathrm{~cm}$ de altura, objetivando a brotação de ramos laterais. Foram realizados todos os tratos culturais necessários para a adequada condução das plantas, conforme recomendações de PEREIRA et al. (2002) para a cultura do pessegueiro na região. Em função da fenologia estudada no ano de 2005, observou-se que as seleções "Jab 484” e "Jab 694” não necessitam de poda de renovação por apresentarem ciclo longo. Dessa forma, a poda de renovação nestes dois genótipos foi realizada somente em novembro de 2004 para o estudo da fenologia em 2005, mas não foi necessária após a colheita de 2005.

Nos anos de 2005 e de 2006, foram avaliadas dez variáveis relacionadas à frutificação, qualidade física de frutos e produtividade. A contagem do número de ramos mistos por planta foi realizada aos 20 dias após a poda de frutificação. Foram contabilizados todos os ramos contendo gemas vegetativas e floríferas e com mais de $10 \mathrm{~cm}$ de comprimento. Aos 75 dias após a aplicação da cianamida hidrogenada, momento do raleio, foram marcados 20 ramos mistos no terço mediano da planta útil de cada parcela, sendo cinco ramos em cada quadrante. Nestes ramos, foi contado o número de frutos antes do raleio. Em seguida, foi realizado o raleio do excesso de frutos, de acordo com PEREIRA et al. (2002), e a contagem dos frutos remanescentes, definindo o número de frutos por ramo depois do raleio. Nestes ramos, contabilizou-se também o número de brotos por ramo, definidos com o mínimo de três folhas.

O número de frutos por planta foi contado aproximadamente aos 90 dias após a aplicação da cianamida hidrogenada. Para tanto, foram considerados os frutos com desenvolvimento normal, em toda a planta. As avaliações físicas dos frutos foram feitas com a amostragem de 20 frutos por parcela, colhidos aleatoriamente, aproximadamente na metade do período da colheita e em estádio "de vez". Foram avaliados o diâmetro equatorial do fruto, na linha de sutura, e o comprimento, ambas as avaliações foram feitas com auxílio de paquímetro digital e expressas em $\mathrm{mm}$. O peso do fruto foi mensurado com balança digital e expresso em $\mathrm{g}$.

A produção por planta foi estimada multiplicando-se o número de frutos por planta pelo peso médio do fruto (em kg) e os dados foram expressos em $\mathrm{kg} \mathrm{pl}^{-1}$. A produtividade por hectare foi estimada multiplicando-se a produção por planta (em kg) pelo número de plantas por hectare (416), dividindo-se por 1.000, sendo os resultados expressos em $t \mathrm{ha}^{-1}$.

O experimento foi instalado em blocos ao acaso com quatro tratamentos (cvs. "Aurora-1" e “Régis” e seleções “Jab 484” e “Jab 694”) e seis repetições de três plantas cada (tomando-se a planta central como útil), totalizando 24 parcelas ou 72 plantas. O espaçamento entre plantas foi de 6 x 4m, resultando em área total de $1.728 \mathrm{~m}^{2}$. Os dados foram submetidos à análise de variância pelo teste $\mathrm{F}$ e as médias foram comparadas pelo teste de Tukey em nível de 5\% de probabilidade de erro.

\section{RESULTADOS E DISCUSSÃO}

O número de ramos por planta (Tabela 1) não diferiu significativamente entre os genótipos no ano de 2005, revelando a homogeneidade da poda de produção realizada. Em 2006, na seleção “Jab 484”, foi possível deixar um maior número de ramos mistos por planta $(426,67)$ em função de apresentar grande volume de copa e pernadas abertas (SALLES, 2002), o que o diferiu estatisticamente em relação aos demais genótipos. Nos quatro genótipos estudados, constatase o grande número de ramos mistos (mais de 250 por planta em 2005 e mais de 300 por planta em 2006), revelando o rápido desenvolvimento das plantas no segundo e no terceiro ano após o transplantio, respectivamente.

Houve diferença estatística significativa entre os genótipos no número de frutos por ramo antes do raleio somente em 2005 (Tabela 1). Nesse ano, "Régis” e "Aurora-1" apresentaram maior número de frutos por ramo em relação às duas seleções. O raleio de frutos se fez necessário nos quatro genótipos em 2005, entretanto, a intensidade foi maior nas cultivares "Régis” e “Aurora1 ”, em que aproximadamente $37 \%$ dos frutinhos tiveram que ser raleados, de acordo com o critério recomendado 
Tabela 1 - Efeito de diferentes seleções e cultivares-copa de pessegueiro, enxertados em “Okinawa” propagados por sementes (2ํㅡ e $3^{\circ}$ ano após o transplantio das mudas) nas variáveis número de ramos por planta após a poda de frutificação, número de frutos por ramo misto antes e depois do raleio, número de brotos por ramo misto e número de frutos por planta. Vista Alegre do Alto, SP, 2006.

\begin{tabular}{|c|c|c|c|c|c|c|c|c|c|c|}
\hline \multirow[t]{2}{*}{ Сopa } & \multicolumn{2}{|c|}{ no ramos/planta } & \multicolumn{2}{|c|}{$\begin{array}{l}\text { no frutos/ramo antes } \\
\text { raleio }\end{array}$} & \multicolumn{2}{|c|}{$\begin{array}{l}\mathrm{n}^{\mathrm{o}} \text { frutos/ramo depois } \\
\text { raleio }\end{array}$} & \multicolumn{2}{|c|}{$\mathrm{n}^{\circ}$ brotos/ramo } & \multicolumn{2}{|c|}{$\mathrm{n}^{\mathrm{o}}$ frutos/planta } \\
\hline & 2005 & 2006 & 2005 & 2006 & 2005 & 2006 & 2005 & 2006 & 2005 & 2006 \\
\hline Régis & $252,00 \mathrm{a}$ & 303,17 b & $2,35 \mathrm{a}$ & 0,79 a & $1,50 \mathrm{ab}$ & $0,79 \mathrm{a}$ & $4,63 \mathrm{a}$ & $4,75 a b$ & $245,67 \mathrm{ab}$ & $139,83 \mathrm{a}$ \\
\hline Jab 484 & $297,50 \mathrm{a}$ & $426,67 \mathrm{a}$ & $1,36 \mathrm{~b}$ & 0,34 a & 1,12 b & $0,34 \mathrm{a}$ & 5,43 a & 5,59 a & 200,83 bc & $136,33 \mathrm{a}$ \\
\hline Jab 694 & $289,31 \mathrm{a}$ & $310,50 \mathrm{~b}$ & $0,60 \mathrm{~b}$ & 0,69 a & $0,44 \mathrm{c}$ & 0,69 a & $5,10 \mathrm{a}$ & $5,12 \mathrm{ab}$ & $93,00 \mathrm{c}$ & 149,33 a \\
\hline Aurora-1 & 276,17 a & $311,17 \mathrm{~b}$ & 2,58 a & 0,62 a & 1,63 a & $0,62 \mathrm{a}$ & 4,16 a & $3,98 \mathrm{~b}$ & 318,67 a & $122,50 \mathrm{a}$ \\
\hline CV (\%) & 16,79 & 20,08 & 31,54 & 82,05 & 24,22 & 82,05 & 21,14 & 17,83 & 31,62 & 62,15 \\
\hline
\end{tabular}

Médias seguidas por letras distintas, na mesma coluna, diferem entre si pelo teste de Tukey em nível de 5\% de probabilidade de erro.

por PEREIRA et al. (2002), o que também resultou em diferença significativa no número de frutos por ramo depois do raleio (Tabela 1). No ano de 2006, as condições climáticas não foram favoráveis à frutificação, pois de maio a setembro a umidade relativa do ar mensal foi menor (70,1\%, 66,4\%, 60,2\%, 52,5\% e 60,4\%, respectivamente) e a insolação mensal foi maior (249,4h, 267,7h, 271,4h, 305,6 e $229,7 h$, respectivamente) em relação à média histórica (73,4\%, 70,5\%, 64,1\%, 58,2\% e 61,4\% de unidade relativa do ar e 228,1h, 223,0h, 248,4h, 240,3h e 198,7h de insolação, respectivamente, para o período de maio a setembro) (VOLPE, 2006a.; VOLPE, 2006b.). Com isso, ocorreram baixas taxas de frutificação nos quatro genótipos estudados e o número de frutos por ramo antes do raleio apresentou valores entre 0,34 (“Jab 484”) e 0,79 ("Régis”), os quais não diferiram significativamente entre si. Com a baixa taxa de frutificação, não houve necessidade de realização do raleio em 2006 (Tabela 1). Provavelmente a associação de baixa umidade relativa do ar e de alta insolação e temperatura durante o florescimento compromete a viabilidade do pólen e a frutificação, o que torna a persicultura uma atividade de risco na região. Por outro lado, quando permanecem relativamente próximas às médias históricas (VOLPE, 2000a.), o surgimento de pragas e de doenças, como a podridão-parda, são desfavoráveis, o que torna o clima da microrregião de Jaboticabal um importante aliado à produção de pêssegos de alta qualidade, com reduzidas aplicações de agrotóxicos (NIENOW, 1997; PEREIRA et al., 2002).

O número de brotos por ramo misto apresentou diferença estatística significativa entre os genótipos somente em 2006, quando “Jab 484" apresentou maior número de brotos em relação ao “Aurora-1”, enquanto que "Régis” e “Jab 694” comportaram-se como intermediários. Os valores observados nos dois anos, acima de quatro brotos por ramo misto, foi considerado satisfatório para suprir o crescimento dos frutos em fotoassimilados.
Segundo RASEIRA et al. (1998), são necessárias entre 30 e 35 folhas para se produzir um pêssego de padrão comercial.

O número de frutos por planta diferiu significativamente entre os genótipos estudados somente em 2005 (Tabela 1). A cultivar “Aurora-1” (com 318,67 frutos por planta) apresentou maior média, ainda que não tenha diferido estatisticamente de "Régis" (245,67 frutos por planta). A seleção “Jab 694” apresentou a menor média (93 frutos por planta) e não diferiu estatisticamente de “Jab 484” (com 200,83 frutos por planta). Em 2006, o número de frutos por planta situou-se entre 122,50 (“Aurora-1”) e 149,33 (“Jab 694”) e não se detectou diferença estatística entre os genótipos. As condições climáticas desfavoráveis ao satisfatório vingamento dos frutos e a não realização da poda de renovação em "Jab 484" e "Jab 694" certamente contribuíram para a não significância estatística.

Constatou-se que a cultivar "Régis" apresenta frutos mais leves e com menor diâmetro e comprimento em relação aos demais genótipos estudados, tanto em 2005 como em 2006 (Tabela 2). Segundo OJIMA et al. (1991), o fruto de "Régis" é de tamanho médio, em torno de $90 \mathrm{~g}$, globoso e praticamente sem ápice, com base peduncular ampla e cavidade rasa. A sutura é pouco nítida e divide o fruto em duas metades simétricas. Apesar de a análise estatística não detectar diferenças significativas em todos os casos, observa-se a tendência de que os frutos de “Aurora-1" são maiores em comprimento e menores em diâmetro, comparativamente aos frutos de "Jab 484" e “Jab 694”. Esta observação resulta no menor peso do fruto de “Aurora-1" em relação às duas seleções (Tabela 2). Estes dados concordam com a descrição do formato dos frutos, sendo arredondado nas duas seleções (SALLES, 1997; SALLES, 2002) e oblongo com ápice medianamente saliente na cultivar "Aurora-1" (OJIMA et al., 1989). Os valores de comprimento, diâmetro e

Ciência Rural, v.38, n.6, set, 2008. 
Tabela 2 - Efeito de diferentes seleções e cultivares-copa de pessegueiro, enxertados em “Okinawa” propagados por sementes (2o e 3o ano após o transplantio das mudas) nas variáveis diâmetro do fruto (mm), comprimento do fruto (mm), peso do fruto (g), produção por planta $\left(\mathrm{kg} \mathrm{planta}^{-1}\right)$ e produtividade por hectare $\left(\mathrm{t} \mathrm{ha}^{-1}\right)$. Vista Alegre do Alto, SP, 2006.

\begin{tabular}{|c|c|c|c|c|c|c|c|c|c|c|}
\hline \multirow[t]{2}{*}{ Copa } & \multicolumn{2}{|c|}{$\begin{array}{l}\text { diâmetro do fruto } \\
\text { (mm) }\end{array}$} & \multicolumn{2}{|c|}{$\begin{array}{l}\text { comprimento do fruto } \\
\text { (mm) }\end{array}$} & \multicolumn{2}{|c|}{ peso do fruto (g) } & \multicolumn{2}{|c|}{$\begin{array}{l}\text { Produção por planta } \\
\qquad\left(\mathrm{kg} \mathrm{pl}^{-1}\right)\end{array}$} & \multicolumn{2}{|c|}{$\begin{array}{l}\text { produtividade por } \\
\text { hectare }\left(\mathrm{t} \mathrm{ha}^{-1}\right)\end{array}$} \\
\hline & 2005 & 2006 & 2005 & 2006 & 2005 & 2006 & 2005 & 2006 & 2005 & 2006 \\
\hline Régis & $48,29 \mathrm{~b}$ & $52,08 \mathrm{c}$ & 48,68 c & 54,17 c & 52,57 c & $71,00 \mathrm{~d}$ & $12,86 \mathrm{bc}$ & 9,58 a & 5,35 bc & $3,98 \mathrm{a}$ \\
\hline Jab 484 & 53,58 a & $57,58 \mathrm{~b}$ & $56,18 \mathrm{~b}$ & $59,16 \mathrm{~b}$ & 80,20 a & $104,78 \mathrm{~b}$ & $15,95 a b$ & $14,04 \mathrm{a}$ & $6,64 a b$ & $5,84 \mathrm{a}$ \\
\hline Jab 694 & 52,67 a & $60,70 \mathrm{a}$ & $56,06 \mathrm{~b}$ & 65,21 a & 79,23 a & 117,90 а & $6,91 \mathrm{c}$ & 17,56 a & $2,88 \mathrm{c}$ & 7,31 a \\
\hline Aurora-1 & 51,70 a & $54,91 \mathrm{~b}$ & 61,66 a & 66,49 a & 69,34 b & 93,84 c & $22,00 \mathrm{a}$ & 11,35 a & 9,15 a & $4,72 \mathrm{a}$ \\
\hline CV (\%) & 2,40 & 3,00 & 2,46 & 3,08 & 6,07 & 6,74 & 32,60 & 49,53 & 32,59 & 49,51 \\
\hline
\end{tabular}

Médias seguidas por letras distintas, na mesma coluna, diferem entre si pelo teste de Tukey em nível de 5\% de probabilidade de erro.

peso de fruto das seleções "Jab 484" e "Jab 694" obtidos no presente estudo são ligeiramente maiores que os descritos por SALLES (2002), fato atribuído às melhores condições de desenvolvimento das plantas em relação às dispensadas durante os trabalhos de seleção dos mesmos.

A produção por planta e a produtividade por hectare (Tabela 2) revelou a superioridade da cultivar "Aurora-1" em condições climáticas normais, observadas no ano de 2005, ainda que não tenha diferido estatisticamente de "Jab 484". Em 2006, os resultados foram prejudicados pelas condições climáticas adversas, que interferiram na frutificação. Nesse ano, constata-se que "Jab 484" e "Jab 694" apresentaram produção e produtividade equivalentes à "Regis" e à “Aurora-1" e revela a satisfatória adaptação de ambas ao inverno ameno e seco. $\mathrm{Na}$ atualidade, "Jab 484" e "Jab 694" são as melhores opções para a microrregião de Jaboticabal na ampliação do período de colheita, pois são duas seleções com maturação em dezembro, apresentam longo ciclo entre a florada e a colheita (SALLES, 2002) e dispensam a poda de renovação após a colheita, o que passa a ser vantajoso com vistas à redução dos custos de produção. Provavelmente a adequação da época de poda e do sistema de condução dessas plantas possa permitir aumentos de produção e de produtividade.

Os valores de produção e de produtividade na cultivar "Régis" foram prejudicados em função do menor peso dos frutos (Tabela 2), uma vez que o número de frutos por planta desta cultivar não diferiu estatisticamente de “Aurora-1" (Tabela 1). As produções de $12,86 \mathrm{~kg} \mathrm{pl}^{-1}$ e de $9,58 \mathrm{~kg} \mathrm{pl}^{-1}$ obtidas em "Régis" (Tabela 2), no $2^{\circ}$ e $3^{\circ}$ anos após o transplantio, respectivamente, situaram-se próximas às produções obtidas em Jundiaí $\left(10,8 \mathrm{~kg} \mathrm{pl}^{-1} \mathrm{e} 16,5 \mathrm{~kg} \mathrm{pl}^{-1}\right)$ e em Monte Alegre do Sul (11,6 $\mathrm{kg} \mathrm{pl}^{-1} \mathrm{e} 12,2 \mathrm{~kg} \mathrm{pl}^{-1}$ ) (OJIMA et al., 1991), o que revela grande potencial produtivo desta cultivar na microrregião de Jaboticabal. Segundo
BARBOSA et al. (1990), a cultivar "Régis” apresenta ciclo (entre a florada e a maturação dos frutos) entre 93 e 98 dias em Jundiaí-SP, e a colheita ocorre em outubro, o que classifica a cultivar como precoce. $\mathrm{Na}$ microrregião de Jaboticabal, observou-se que o ciclo desta cultivar fica entre 72 e 74 dias, o que permite classificá-la como ultraprecoce, sendo uma excelente opção de dupla finalidade para esta microrregião.

\section{CONCLUSÕES}

A frutificação das cultivares "Régis" e “Aurora-1" e das seleções "Jab 484" e "Jab 694" é satisfatória em condições climáticas normais no município de Vista Alegre do Alto-SP.

A cultivar "Régis" pode apresentar produção e produtividade equivalentes à "Aurora-1", podendo se tornar opção para produção ultraprecoce com frutos de dupla finalidade, ainda que sejam menores e mais leves em relação à "Aurora-1", “Jab 484” e "Jab 694". As seleções “Jab 484" e "Jab 694" apresentam potencial para o cultivo no Município de Vista Alegre do Alto-SP por apresentarem frutos com características de dupla finalidade, serem mais pesados que "Aurora1 " e poderem atingir produção e produtividade equivalentes a esta cultivar.

\section{AGRADECIMENTOS}

Os autores agradecem à Fundação de Amparo à Pesquisa do Estado de São Paulo (FAPESP), pelo apoio financeiro (Processo no 04/12110-6), e ao Sr. Valdenir Rossi, proprietário da "Fazenda Santa Alzira” (Vista Alegre do Alto, $\mathrm{SP})$, pela concessão da área experimental, das máquinas, dos equipamentos e mão-de-obra para condução do experimento.

\section{REFERÊNCIAS}

CATI. Mapa da Agricultura Paulista. Projeto Lupa, pêssego. 1997. Capturado em 10 out. 2002. Online. Disponível na Internet: http//www.cati.sp.gov.br/servicos/mapa/culturas/ pessego.htm. 
BARBOSA, W. et al. Época e ciclo de maturação de pêssegos e nectarinas no estado de São Paulo. Bragantia, Campinas, v.49, n.2, p.221-226, 1990.

BARBOSA, W. et al. Melhoramento do pessegueiro para regiões de clima subtropical-temperado: realizações do Instituto Agronômico no período de 1950 a 1990 . Campinas: Instituto Agronômico, 1997. 22p. (Documentos IAC, 52).

BARBOSA, W. et al. Distribuição geográfica e diversidade varietal de frutíferas e nozes de clima temperado no Estado de São Paulo. Revista Brasileira de Fruticultura, Jaboticabal, v.25, n.2, p.341-344, 2003.

ESPÍRITO SANTO. Produtores capixabas se mobilizam para viabilizar pólo de pêssego na região serrana. Capturado em 22 mar. 2007. Online. Disponível na internet: h t t p : // w w w.e s.gov.br/site/noticias/ show_poput.aspx?noticiaId=99660286.

NIENOW, A.A. Comportamento morfológico, fenológico e produtivo de cultivares de pessegueiro (Prunus persica (L.) Batsch), submetidos à poda de renovação após a colheita, na região de Jaboticabal, SP. 1997. 171f. Tese (Doutorado em Agronomia) - Curso de Pós-graduação em Agronomia, Universidade Estadual Paulista, Faculdade de Ciências Agrárias e Veterinárias.

OGATA, T. Comportamento de cultivares de pessegueiro, em plantio adensado, submetido à poda drástica, em Anápolis, GO. In: CONGRESSO BRASILEIRO DE FRUTICULTURA, 9., 1987, Campinas. Anais... Campinas: SBF, 1988. p.663-666.

OJIMA, M. et al. “Aurora-1” e "Aurora-2": novas cultivares de pêssego doce de polpa amarela. In: CONGRESSO BRASILEIRO DE FRUTICULTURA, 10., 1989, Fortaleza. Anais... Fortaleza: SBF, 1989. p.422-425.

OJIMA, M. et al. "Régis" - nova cultivar de pêssego para mesa e conserva. Revista Brasileira de Fruticultura, Cruz das Almas, v.13, n.3, p.293-296, 1991.

OLIVEIRA, J.B. et al. Mapa pedológico do Estado de São Paulo: legenda expandida. Campinas: Instituto Agronômico; Rio de Janeiro: Embrapa-Solos, 1999. 64p.

PEREIRA, F.M. et al. Tecnologia para a cultura do pessegueiro em regiões tropicais e subtropicais. Jaboticabal: Funep, 2002. 62p.

PEREIRA, F.M.; MAYER, N.A. Pessegueiro: tecnologias para a produção de mudas. Jaboticabal: Funep, 2005. 65p.

RAIJ, B. Van. et al. Recomendações de adubação e calagem para o Estado de São Paulo. Campinas: IAC, 1996. (Boletim Técnico, 100).
RASEIRA, A. et al. Instalação e manejo do pomar. In: MEDEIROS, C.A.B.; RASEIRA, M. do C.B. A cultura do pessegueiro. Brasília: Embrapa SPI; Pelotas: Embrapa CPACT, 1998. p.130-160.

RASEIRA, M. do C.B.; NAKASU, B. Cultivares: descrição e recomendação. In: MEDEIROS, C.A.B.; RASEIRA, M. do C.B. A cultura do pessegueiro. Brasília: Embrapa SPI; Pelotas: Embrapa CPACT, 1998. p.29-99.

SALLES, L.C. Comportamento e seleção de plantas de pessegueiro [Prunus persica (L.) Batsch] originadas de polinização aberta do cultivar Biuti. 1997. 113f. Dissertação (Mestrado em Agronomia) - Faculdade de Ciências Agrárias e Veterinárias, Universidade Estadual Paulista, Jaboticabal.

SALLES, L.C. Comportamento e seleção de plantas de pessegueiro [Prunus persica (L.) Batsch] originadas de polinização aberta do cultivar Biuti, para a região de Jaboticabal-SP. São Paulo: FAPESP, 2002. 163p.

VOLPE, C.A. (Coord.). Estação agroclimatológica: valores médios do período 1971-2000. 2000a. Capturado em 13 fev. 2007. Online. Disponível na internet: http://www.exatas.fcav. unesp.br/estacao/est_normal.htm.

VOLPE, C.A. (Coord.). Estação agroclimatológica: balanço hídrico. 2000b. Capturado em 13 fev. 2007. Online. Disponível na internet: http://www.exatas.fcav.unesp.br/estacao/est_ balanco.htm.

VOLPE, C.A. (Coord.). Estação agroclimatológica: resenha meteorológica do período 1971-2000. 2000c. Capturado em 13 fev. 2007. Online. Disponível na internet: http:// www.exatas.fcav.unesp.br/estacao/est_resanha.htm.

VOLPE, C.A. (Coord.). Estação agroclimatológica: umidade relativa do ar do ano 2006. 2006a. Capturado em $13 \mathrm{fev}$. 2007. Online. Disponível na internet: http://www.exatas. fcav.unesp.br/estacao/graf_ano_atual_2004.htm.

VOLPE, C.A. (Coord.). Estação agroclimatológica: insolação mensal do ano 2006. 2006b. Capturado em 13 fev. 2007. Online. Disponível na internet: http://www.exatas.fcav.unesp.br/ estacao/graf_ano_atual_2004.htm.

YAMANAKA, R.Y. Análise do número de horas com temperaturas do ar igual ou abaixo de $7,0^{\circ} \mathrm{C}$ e igual ou abaixo de $13,0^{\circ} \mathrm{C}$ e disponibilidade de graus-dia em Jaboticabal, SP. 1992. 83f. Monografia (Trabalho de Graduação em Agronomia) - Universidade Estadual Paulista, Faculdade de Ciências Agrárias e Veterinárias. 